$A B C D$ Arq Bras Cir Dig 2019;32(1):e1430

DOI: /10.1590/0102-672020180001e1430

\section{LUMEN-APPOSING METAL STENT AND ELETROCAUTERY ENHANCED DELIVERY SYSTEM (HOT AXIOSTM) FOR DRAINAGE OF WALLED-OFF NECROSIS: THE FIRST BRAZILIAN CASE REPORT}

Drenagem ecoguiada de necrose pancreática delimitada com Hot Axios $^{T M}$ : primeiro relato de caso no Brasil

Diogo Turiani HOURNEAUX DE-MOURA'1, Galileu Ferreira Ayala FARIAS ${ }^{1}$, Vitor Ottoboni BRUNALDI ${ }^{1}$, Caio Vinicius TRANQUILLINI ${ }^{1}$, Marcos Eduardo Lera DOS-SANTOS ${ }^{1}$ Sérgio Eijii MATUGUMA ${ }^{1}$, José JUKEMURA ${ }^{1}$, Eduardo Guimarães HOURNEAUX DE-MOURA ${ }^{1}$

How to cite this article: Hourneaux-de-Moura DT, Farias GFA, Brunaldi VO Tranquillini CV, Dos-Santos MEL, Matuguma SE, Jukemura J, HourneauxDe-Moura EG. Lumen-apposing metal stent and eletrocautery enhanced delivery system (Hot Axios $\left.{ }^{\mathrm{t}}\right)$ for drainage of walled-off necrosis: the first brazilian case report. ABCD Arq Bras Cir Dig. 2019;32(1):e1430. DOI: $/ 10.1590 / 0102-672020180001 \mathrm{e} 1430$

From the ${ }^{1}$ Endoscopia Digestiva, Hospital da Clínicas, Faculdade de Medicina Universidade de São Paulo, SP ('Digestive Endoscopy Service, Clinics Hospital, Medical School, University of São Paulo), São Paulo, SP, Brazil.

\section{Correspondence:}

Diogo Turiani Hourneaux de-Moura

E-mail:dthmoura@hotmail.com; galileufaf@gmail.com

HEADINGS - Pancreatitis acute necrotizing. Pancreatic pseudocyst Endoscopy.

DESCRITORES - Pancreatite necrosante aguda. Pseudocisto pancreático. Endoscopia.

Financial source: none

Conflict of interest: none

Received for publication: 16/03/2017

Accepted for publication: 06/11/2018

INTRODUCTION

$\mathrm{P}$ ancreatic fluid collections are acute complications following pancreatitis ${ }^{1}$. They are usually self-limited and further interventions are only indicated for growing, symptomatic or complicated cases, such as infected or bleeding collections $\mathbf{s}^{2}$. Currently, EUS-guided drainage is the gold-standard treatment ${ }^{7}$. The AXIOS is a lumen-apposing metal stent specifically developed for the treatment of pancreatic fluid collections. The juxtaposed lumen improved the limitations of others drainage devices. This characteristic reduces the migration and obstruction rates, and the necessity of stent substitutions. The Hot-AXIOS is an insulated delivery system plugged into the stent that allows transmural deployment of the AXIOS and exempts the guidewire placement and dilation of the tract $\mathrm{t}^{10}$.

The objective of this study (Institutional Ethic Committee approval number 54011816.6.0000.0068) was to report the first
Brazilian case of EUS-guided transmural drainage of a walledoff necrosis with the HOT-AXIOSTM system and to describe the technique for the deployment.

TECHNIQUE

The initial steps to perform the procedure are: 1) wet the AXIOS catheter with sterile water or normal saline; 2 ) insert the AXIOS device system into the working channel; 3 ) connect the electrosurgical generator and set it to pure cut; 4) unlock the catheter lock; 5) advance the black catheter control hub until the catheter is seen by the ultrasound image; 6 ) energize the device and advance the catheter until the target structure; 7 ) lock the catheter when it is at $3 \mathrm{~cm}$ inside the target structure; 8) power off the generator and unplug the active cable from the AXIOS handle; 9) deploy the first flange taking off the yellow safety clip; 10) unlock the stent lock; 11) slide the stent deployment hub upwards until the stent deployment hub locks into place at the number 2 arrow.

To promote the alignment of the stent it's necessary to unlock the catheter lock; to slide the catheter control hub upwards until at least 2 to $3 \mathrm{~mm}$ of the black catheter shaft marker is visible in the Gl tract; finally, lock the catheter lock.

Next, is the deployment of the second flange made through unlocking the stent lock; sliding the stent deployment hub upwards towards the number 4 arrow; confirming that the second flange is deployed and visible in the GI tract, and finally, rotate counterclockwise the luer lock and remove the AXIOS delivery system.

\section{CASE REPORT}

A 42-years-old alcoholic man was evaluated for a 30-day history of abdominal pain and postprandial vomiting. He referred two previous hospitalizations for acute pancreatitis. Physical examination was unremarkable. Laboratory studies revealed a slight increase of pancreatic enzymes. Magnetic resonance imaging showed a $13 \mathrm{~cm}$ collection with thick content in the pancreatic neck. The upper endoscopy found an important bulging in the posterior gastric wall and the endoscopic ultrasound revealed a $15.7 \times 7.2 \mathrm{~cm}$ pancreatic cyst, predominantly anechoic, with some mobile heterogeneous material, consistent with walledoff necrosis (Figure 1).

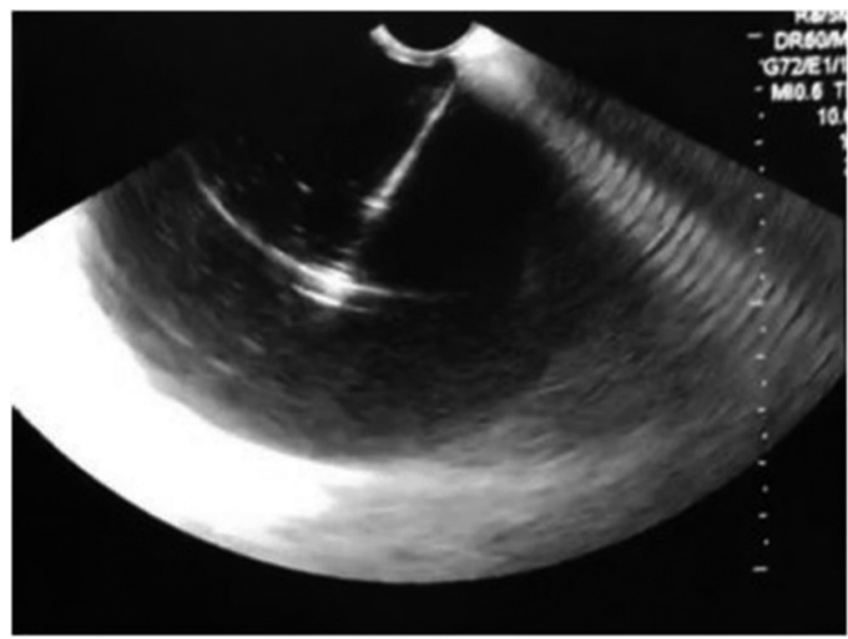

FIGURE 1 - Puncture of the pancreatic cyst, predominantly anechoic, with some mobile heterogeneous material, consistent with walled-off necrosis

Due to the diagnosis of symptomatic walled-off necrosis, we opted for an endoscopic drainage with a 10x10 mm HOTAXIOS $^{\mathrm{TM}}$ stent (Figure 2). The patient was under general 
anesthesia. After puncture, there was an immediate output of a brownish secretion with necrotic solid components (Figure 2). The total duration of the procedure was $20 \mathrm{~min}$ and the time required for drainage was $4 \mathrm{~min}$. We did not use fluoroscopy and there were no immediate complications.

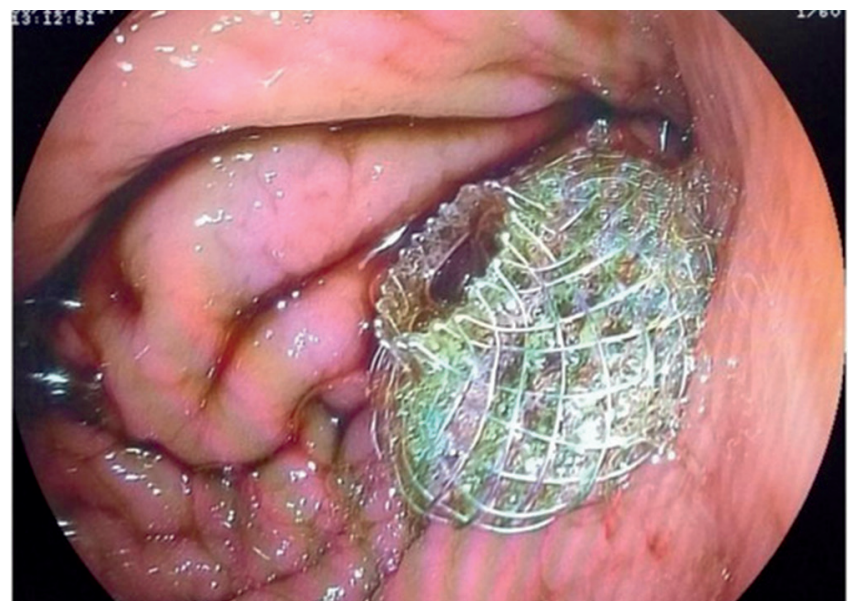

FIGURE 2 - Endoscopic drainage with a 10×10 mm HOT-AXIOSTM stent with an immediate output of a brownish secretion with necrotic solid components

The patient was discharged three days later, asymptomatic. On the $7^{\text {th }}$ post-drainage day, he underwent a new upper endoscopy and a pediatric endoscope was passed $(5.4 \mathrm{~mm}$ in diameter) through the stent into the cyst cavity. Around $80 \%$ of the walled-off necrosis was collapsed and there was a small amount of fibrin with no clots or necrotic tissue. We washed it with $300 \mathrm{ml}$ of $0.9 \%$ saline.

On the $14^{\text {th }}$ post-drainage day, we performed another upper endoscopy and an ERCP for assessment of the main pancreatic duct. Firstly, we tried to introduce a typical gastroscope through the stent but it was not possible due to the complete collapse of the prosthesis. Then, we instilled contrast through the stent and we notice complete reflux back to the gastric chamber, confirming the complete collapse of the collection. Pancreatography revealed a stricture in the transition of the head and neck but no fistula. We performed a pancreatic sphincterotomy and placed a $7 F \times 10 \mathrm{~cm}$ straight plastic stent through the stricture. After deployment of the pancreatic stent, we removed the Hot-AXIOS using a foreign body forceps (Figure 3). The patient was asymptomatic and was discharged $24 \mathrm{~h}$ after the ERCP procedure.

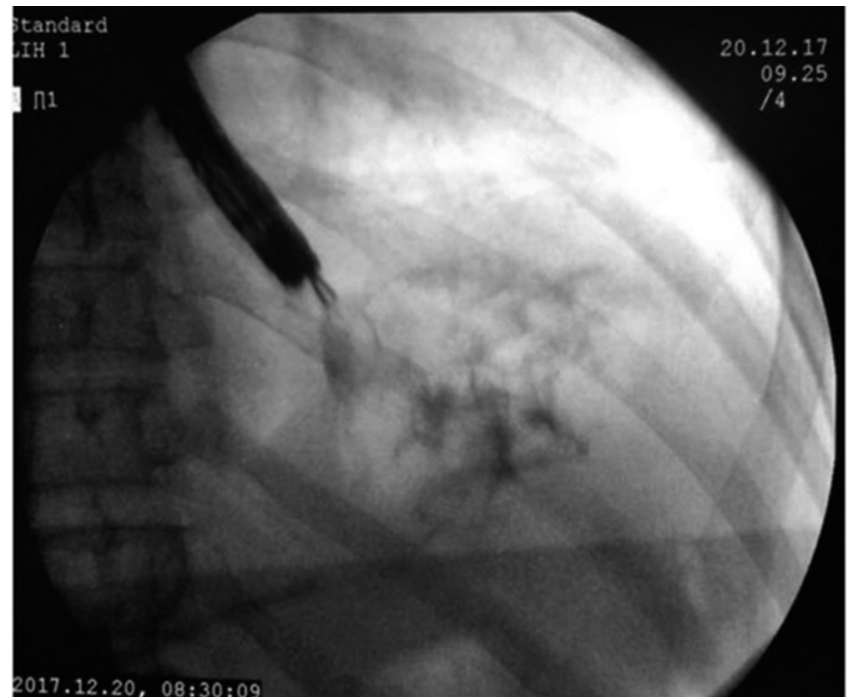

FIGURE 3 - Hot-AXIOS ${ }^{\text {TM }}$ removed using a foreign body forceps
On the $30^{\text {th }}$ post-drainage day, a new abdominal CT showed complete resolution of the pancreatic collection (Figure 4). The patient is currently on two months follow-up and remains asymptomatic. An ERCP is planned on the $3^{\text {rd }}$ month evaluation for removal of the pancreatic stent.

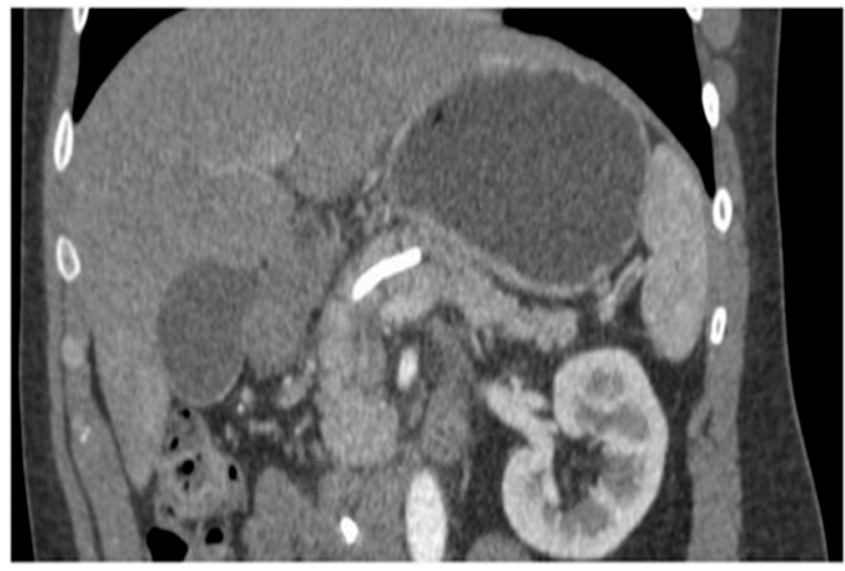

FIGURE 4-Abdominal CT showed complete resolution of the pancreatic fluid collection

\section{DISCUSSION}

Invasive procedures directed at pancreatic fluid collections are indicated for symptomatic, infected, or growing cysts, preferably at least four weeks after the onset ${ }^{6}$. Treatment can be performed by surgery, endoscopy or interventional radiology (percutaneous drainage). Surgical treatment is the most invasive modality and carries significant morbidity, whereas percutaneous drainage presents a higher incidence of fistulas and recurrence rates $^{3}$. Currently, the endoscopic treatment is the gold-standard because it is less invasive while highly effective ${ }^{7}$.

Stents with an internal diameter equal to or greater than 10 $\mathrm{mm}$ allow direct passage of the endoscope into the collection. However, we did not perform direct endoscopic necrosectomy in the first procedure due to the risk of migration. In our unit, we employ a step-up approach, that is, from the simplest to the most complex procedure according to the patient's clinical response. Initially, we perform a simple drainage, followed by unclogging the stent with saline solution and hydrogen peroxide (if obstructed) and, ultimately, irrigation with a nasocystic drain. If all these steps fail, we indicate the direct endoscopic necrosectomy. Using a similar step-up approach, Nabi Z et al ${ }^{4}$ diminished the need of the endoscopic necrosectomy from $40 \%$ to $10 \%$ of cases.

The Hot-AXIOS is an improvement of the standard AXIOS that carries an insulated delivery system plugged into the lumenapposing metal stents, allowing cauterization and introduction of the stent simultaneously. This system exempts punctures, guidewire placement and dilation of the tract. Therefore, it reduces the risk of procedure-related complications such as fistulas, leaks to abdominal cavity and loss of the puncture during the exchange of devices ${ }^{5,9}$

Walter et al ${ }^{8}$ performed a multicenter prospective study enrolling 61 patients: 15 pancreatic pseudocysts and 46 walledoff necrosis. Technical success was achieved in $93 \%$ in the pancreatic pseudocysts group and in $81 \%$ of the remainder in the walled-off necrosis group. They performed the endoscopic necrosectomy in $59.6 \%$ of patients with it, and $19 \%$ of them required more than one procedure. Adverse events occurred in $9 \%$. There was a detachment of the AXIOS stent in three cases during debridement and three spontaneous migration of the lumen-apposing metal stents. The stents were removed after a mean of 32 days after the procedure in $82 \%$ of the patients.

Despite being only recently available in our country and 
a more expensive device, it has already been proved effective in several countries. Further experiences with the Hot-AXIOS device in our unit will allow our personal evaluation of the real effectiveness and safety profile. In this first case using the new HOT-AXIOS device, we experienced technical and therapeutic success in a short period of time without any adverse events.

\section{REFERENCES}

1. Atlanta classification and definitions by international consensus. Gut 2013; 62:102.

2. Bradley EL, Clements JL, Gonzalez AC. The natural history of pancreatic pseudocysts:aunified conceptofmanagement.AmJSurg.1979;137:135-141.

3. Mortele KJ, Girshman J, Szejnfeld D et al (2009) CT-guide percutaneous catheter drainage of acute necrotizing pancreatitis: clinical experience and observations in patients with sterile and infected necrosis. AJR Am J Roentgenol. 192:110-116
4. Nabi Z, Basha J, Reddy DN: Endoscopic management of pancreatic fluid collections-revisited. World J Gastroenterol;23:2660-2672.

5. Teoh AY, Binmoeller KF, Lau JY. Single-step EUS-guided puncture and delivery ofalumen-apposing stentforgallbladderdrainageusing a novel cautery-tipped stent delivery system. GastrointestEndosc. 2014:80:1171.

6. Tsiotos GG, Sarr MG (1999) Management of fluid collections and necrosis in acute pancreatitis. Curr Gastroenterol Rep 1:139-144

7. Varadarajulu S, Bang JY, Sutton BS, Trevino JM, Christein JD, Wilcox $\mathrm{CM}$. Equal efficacy of endoscopic and surgical cystogastrostomy for pancreatic pseudocyst drainage in a randomized trial. Gastroenterology 2013; 145: 583-90

8. Walter D, Will U, Sanchez-Yague A, et al. A novel lumen-apposing metal stent for endoscopic ultrasound-guided drainage of pancreatic fluid collections: a prospective cohort study. Endoscopy. 2015;47:63-67.

9. Weilert F, Binmoeller KF. Specially designed stents for translumenal drainage. Gastrointest Interv. 2015:4:40-45.

10. Yamamoto N, Isayama H, Kawakami H, et al. Preliminary report on a new, fully covered, metal stent designed for the treatment of pancreatic fluid collections. Gastrointest Endosc 2013;77:809-814. 